\title{
DÜBLIN
}

Technological University Dublin

ARROW@TU Dublin

\section{Integrated Scenarios for Energy: a Methodology for the Short Term}

\author{
Tadhg O'Mahony \\ Technological University Dublin, tadhg.omahony@tudublin.ie
}

Follow this and additional works at: https://arrow.tudublin.ie/futuresacart

Part of the Growth and Development Commons, and the Other Economics Commons

\section{Recommended Citation}

O'Mahoney, T. Integrated scenarios for energy: a methodology for the short term. Working paper, DIT, 2013.

This Working Paper is brought to you for free and open access by the Futures Academy at ARROW@TU Dublin. It has been accepted for inclusion in Articles by an authorized administrator of ARROW@TU Dublin. For more information, please contact arrow.admin@tudublin.ie, aisling.coyne@tudublin.ie, gerard.connolly@tudublin.ie.

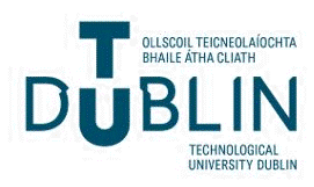




\title{
Working Paper
}

\section{Integrated scenarios for energy: a methodology for the short term}

\author{
Tadhg O’ Mahony ${ }^{\mathrm{a}, *}$,
}

${ }^{\mathrm{a}}$ The Futures Academy, Dublin Institute of Technology, Dublin 1, Ireland

\begin{abstract}
Quantitative point forecasts of energy and emissions have experienced difficulty with responding to uncertainty. Accuracy issues arise even in the short term with consequences for policy. The technique of scenario analysis is increasingly applied in scientific inquiry on the long term but it also has utility in the short term. This paper presents a discussion of the use of forecasts for prediction and proposes integrated or 'hybrid' exploratory qualitative and quantitative scenarios in its stead. Various methodological issues are explored towards formulation of a scenario development process. Integrated scenarios structure thinking on the future, bound uncertainty, document important assumptions, aid communication, widen perspectives, can explore new dynamics and permit the exploration of 'softer' issues in development paths such as governance, social and cultural drivers. These can be crucial to outcomes but are not captured by quantitative approaches alone. An example of the technique employed to construct integrated scenarios for Ireland to 2020 is presented, which as a process is applicable with diverse quantitative techniques. The advancement of more broad holistic perspectives on development and processes of change is policy relevant in all states, for which purpose integrated scenarios are an ideal analysis and mainstreaming tool even on short time scales.
\end{abstract}

Keywords: Scenario, Forecast, Energy, Short-term, Integrated

\footnotetext{
* Corresponding author Present Address: Systems Analysis Unit, IMDEA Energy Institute, Av. Ramóndela Sagra 3, Móstoles, Spain; Tel.: +34 917371153; fax: +34917371140, E-mail address: tadhg.omahony@imdea.org
} 


\section{Working Paper}

Trying to predict the future is like trying to drive down a country road at night with no lights while looking out the back window.

-Peter F. Drucker

\section{Introduction}

Energy and emissions analysis, the development of policy and the reporting of progress require insight into driving forces of change and potential future evolution. Energy and emissions are both dependent on, and influenced by, a wide development domain which is complex in evolution and uncertain in outcome. Conceptual, theoretical, methodological, empirical and praxis issues arise with all techniques proposing insight into the future. Because of the monopoly of short term point forecasts and projections in these tasks, issues of accuracy are of much concern. There is evidence of significant problems with these approaches which nonetheless continue to dominate with inevitable consequences for policy. This paper has a methodological focus, discussing the use of point forecasting as a predictive tool for the short and medium term and innovates by proposing the hybrid exploratory scenario approach in its stead. It is original in discussing methodologies, techniques and processes relevant to the development of short term scenarios of energy and related emissions. As an example, the process used in generating scenarios for Ireland to 2020 is presented from [1]. As per Varho and Tapio [2], most of the required tools and techniques are well documented but the combination is novel, particularly in the context of short term scenarios. In this paper Section 2 discusses forecast accuracy and section 3 discusses methodological issues in developing short term energy and related emission scenarios. Section 4 briefly reviews the technique used for development of short term hybrid exploratory scenarios for Ireland. Section 5 offers concluding remarks on the issues arising and potential options to move forward methodologically. 


\section{Working Paper}

\section{Forecast accuracy and scenarios}

The ex-post evaluation of energy or emissions forecast accuracy has not often been conducted. Linderoth [3] described large forecast errors in IEA member countries' arising not only from the discontinuities of the oil crises but also in more stable periods. Errors sometimes conceal the sum of considerable positive and negative forecast errors in the sectors, particularly with industry and transport. Linderoth noted that the underestimate of transport can have particular consequences for emissions reduction policy [3]. In looking at forecast error for the US, Winebrake and Sakva found a low mean percentage error for total energy consumption concealing an average $5.9 \%$ overestimate for the industry sector and 4.5\% underestimate for the transport sector [4]. In general, errors occur not only in absolute totals and sectoral consumption, but in GDP growth rates, energy intensity improvement and in fuel mix [5]. This reduces the potential accuracy of related forecasts of greenhouse gas (GHG) emissions and as they are an input into policy processes this has further consequences downstream. Errors can occur even on short time-scales. Large errors can occur even when the forecast year is close to the review year [3].

At the United Nations Framework Convention on Climate Change (UNFCCC) Dublin workshop for Annex I parties on the preparation of the fourth national communications, it was suggested that in some cases Annex I nations need to produce additional scenarios [6]. Although the likely statistical dispersion of results is inevitably greater in the longer term, the statistical dispersion is potentially still large in the short term. Irreducible and omnipresent complexity and uncertainty corresponds with the difficulties in short term forecasting. This uncertainty is a challenge to probabilistic and predictive methodologies and suggests that scenarios have utility in bounding uncertainty.

While forecasts are useful in some contexts they can also give an illusion of certainty [7]. Allied to the issue of accuracy of forecasts are issues pertaining to the audience of energy 


\section{Working Paper}

and emissions forecasts. Those outside of the modeling process, including decision-makers, analysts and the public, may not be fully aware of the caveats attached, their significance, or how to incorporate the resultant uncertainty effectively into their frame of reference. A host of cognitive biases arise for forecast audiences such as overconfidence and confirmation bias [8]. Environmental and technical assessments altered actors' expectations, knowledge and behaviours [9]. Whereas scenarios can widen perspectives, the more limited view provided by forecasts is consequently subject to strategic risks and political and ethical concerns.

UNFCCC reporting guidelines describe three GHG projections required in national communications; "With Measures" (WM) of currently implemented and adopted policies and measures, "With Additional Measures" (WAM) of planned policies and measures and "Without Measures" (WOM) excluding all policies and measures implemented, adopted or planned after the starting year referred to as the "baseline" or "reference" projection [10]. Parties are given the option of reporting sensitivity analysis, but are recommended to limit the number of scenarios. While this process may appear less cumbersome in analytical terms, projection exercises that rely on single point forecasts will inevitably be subject to greater uncertainty and difficulties with accuracy, as opposed to a range provided for by baseline scenarios. Strategic policy implications will arise where forecast inaccuracy increases. It could reasonably be assumed that given the importance of UNFCCC requirements in national energy and emissions policy that these rules encourage the continuation of point forecasts as the standard approach.

\section{Scenario analysis}

\subsection{Background}

Scenario analysis has a rich history in an increasing number of sectors and disciplines [11] as a tool to deal with uncertainty. An expanding array of business, community, policy 


\section{Working Paper}

and research contexts use scenarios with highly varied objectives -better management, consciousness raising, conflict resolution, policy advice and research [12]. The variety of users and contexts has led to the evolution of a broad diversity of approaches and methodologies for scenario development [13]. Scenario analysis has been increasingly applied with energy due to the difficulties in providing accurate forecasts [14], and separately due to the need for tools for imagining, discussing, and preparing for equally 'plausible' futures. These two streams of scenario analysis could be respectively described as "inquirydriven" and "strategy-driven" [15]. ${ }^{1}$ Inquiry-driven scenario analysis is conducted to meet the needs of the scientific community through expanding knowledge and as an input into policy analysis. Strategy-driven scenario analysis stems in origin primarily from the business community for corporate planning. The scientific credibility of strategy-driven scenarios is sometimes dismissed although it must be noted such scenarios are not necessarily intending scientific credibility. Multiple scenarios can be effectively employed to counteract 'future myopia' [16] and can assist in countering the multitude of cognitive biases that can arise with forecasts [8]. This is particularly important in a world of surprise and discontinuity in which policy must be formulated.

Scenarios allow structured thinking on the future based on the evolution of aspects such as driving forces, trends, themes, events and cause-effect logics. With the scenario analysis approach the objective is not prediction, but to construct and articulate several different futures and the paths to them [17]. The advancement of the science of climate change has required insight into future climate change and impacts. This is dependent on the evolution of human factors such as anthropogenic GHG emissions. Given the uncertainty of future development, scenarios were used in the Special Report on Emission Scenarios (SRES) of the Intergovernmental Panel on Climate Change (IPCC) as the appropriate tool for

\footnotetext{
${ }^{1}$ These threads seem to provide a concise typology but are described by Alcamo [15] as only caricatures of scenario types.
} 


\section{Working Paper}

the exploration of the future evolution of global GHG emissions to 2100 [18]. As many social and biophysical systems are complex in evolution and poorly understood, the scenarios were neither predictions nor forecasts but were used to explore equally plausible images of future development. The scenarios were used as linking tools that integrate qualitative narratives or storylines and quantitative modelling.

\subsection{Applying scenario analysis to energy and emissions}

In the literature, scenarios are used for a plethora of purposes, consequently it is the objectives of the exercise that dictate the characteristics of scenarios, the framework and process used and the form of the scenarios [19]. The terminology used in describing possible future conditions in the context of emissions is often interchangeable in the literature. Some useful distinctions are defined by Holmes [20]. Whereas projections, project forward past trends and forecasts are predictive and seek to determine the most likely future, scenarios can look at diverging trends and the potential unfolding of new dynamics. Rather than prediction, scenarios seek to describe a 'spectrum of possibility'. This is a bounded envelope of probability that covers the range of plausible outcomes. ${ }^{2}$ Environmental and emission scenarios are used in contexts where dynamic complex systems are subject to uncertainties. These uncertainties include inadequate scientific understanding, data gaps and the inherent uncertainties of future events [18], Raskin et al. outlined sources of indeterminacy as ignorance, volition and surprise [21]. Ghanadan and Koomey make the distinction where scenarios explore uncertainties through insightful pathways forecasts seek the most likely pathway and characterisation of uncertainty [22]. Forecasts have a poor record in this regard [22] and have routinely overestimated consumption and underestimated uncertainties [7]. Often forecasts and projections are based on producing 'Business As Usual' (BAU) or central

\footnotetext{
${ }^{2}$ In addition a common use of scenarios is to quantify savings potentials from policy, technology or behavioural changes [22].
} 


\section{Working Paper}

'best guess' estimates and the high/ low, optimistic/ pessimistic or policy variants of these.

Criticisms of this approach include that it is evident that a future involving no change as in BAU is virtually impossible [23]. The European Environment Agency discuss how the use of variations on a single scenario is less desirable than an approach that incorporates multiple perspectives through divergent scenarios [24]. Formulating a range of emission scenarios is an appropriate technique to encompass uncertainties and deliver policy insights [18]. Issues also arise as forecasts can reflect a particular set of values or interests promoted as 'objective' information. ${ }^{3}$ A preoccupation with point forecasts may not be appropriate to either scientific inquiry ${ }^{4}$ or to strategic thinking in decision-making.

\subsection{Qualitative and quantitative approaches}

The issue of complex problems ${ }^{5}$ has a particular salience in the context of emission scenarios and suggests the use of 'complex scenarios' in analysis [11]. This involves combining qualitative and quantitative methods in the analysis of trends and underlying themes and is the frontier of scenario research today [12]. The evolution of complex nonlinear processes can be explored by alternative dynamics beyond trend extrapolations and 'dynamics as usual'. A key problem with deterministic quantitative approaches is the static nature of models while there is nothing static in the economy [7]. According to Craig et al. [7] energy forecasting necessarily makes implicit assumptions about human behaviour including social, institutional, personal and human innovation. Recognising the prime

\footnotetext{
${ }^{3}$ A science-policy nexus exists as technological and economic rationalities are implicitly embedded in models. This opens the question of the world-view, values and philosophy underpinning supposedly 'objective' scientific information. This information can reflect specific futures that are profitable or preferable to certain interests or can be used to legitimise results rather than guide policy [25]. Using scenarios offers an approach to make world views more explicit, through the description of underlying themes in narratives. They can also be used to document assumptions used in modelling. If used incorrectly or towards a particular bias they could also become subject to this limitation.

${ }^{4}$ Craig et al. [7] and Smil [26] are severely critical of long-term quantitative point forecasts due to a "dismal" forecasting record and "false" insights that are potentially counterproductive. Smil suggests exploratory forecasts of a range of plausible alternatives as a "sensible approach" but places particular emphasis on contingency and normative scenarios.

5 "Complex problems" are described as a tangled web of problems (multi-problem), the issues concerned transcend disciplines (multi-dimensional) and underlying processes interact at various scales (multi-scale) [27].
} 


\section{Working Paper}

importance of such drivers, Raskin et al. [12] describe culture, power and values as the conditioning framework or 'ultimate drivers' through which the indirect socio-economic drivers such as population, economic and technological drivers produce an environmental impact. These ultimate drivers can be incorporated in scenarios through integration of qualitative information, a process largely ignored by forecasting exercises. Swart et al. discussed how in sustainability science the utility of scenario analysis is complimented by the imperative of the qualitative element and proposed; the elevation of the non-quantifiable cultural, institutional and value aspects of the integrated system [28]. This avoids limiting the analysis to quantifiable aspects which may not be the most crucial. However, a dualism in emission scenarios has existed in two largely non-overlapping streams of inquiry in quantitative modelling and qualitative narratives [29]. The main differences between model based and non-model based scenarios is the technical and economic detail in the former and social, political and cultural developments in the latter [25]. While these are seen as separate challenges, recent developments in scenario analysis seek to bridge this gap [18]. The key characteristics of these two approaches have been outlined by Morita et al. [30]. Qualitative scenarios are literary exercises aimed at holistic sketches of the future. They have a greater power to posit system shifts, surprise and to include critical factors that defy quantification such as values, cultural shifts and institutional features. They may appear arbitrary, idiosyncratic and weakly supported. Quantitative formal models seek mathematical representation of key features of human and/or environmental systems in order to represent the evolution of the system under alternative assumptions. They are useful for examining futures that result from variations of quantitative driving variables, and they offer a systematic and replicable basis for analysis.

The limits of deterministic modelling and descriptive analyses shown in the first decades of emission scenarios have encouraged the advancement in the literature of the 


\section{Working Paper}

synthesis of approaches as a way forward [29]. The combination of these two approaches can make scenarios more robust [11] and give structural variance and methodological diversity to the approach [30]. Following this synthesis approach, as illustrated in Fig. 1 from the SRES, scenarios are linking tools of qualitative narratives about the future and quantitative formulations based on modelling. These integrated or hybrid scenarios consider the complex interplay and evolution of the system across and within alternatives. They also have a function in communication and aid mitigation analysis and policy-making, by explaining the 'all important' social, political and technological context [18]. The use of the narratives to structure thinking on the alternative development pathways not only makes scenarios more believable but can ensure that they do not become an arbitrary numerical combination of quantitative variables and can make assumptions more explicit. In parallel, the quantitative scenarios are complimentary to the qualitative narratives. They are used to check consistency, to provide relevant numerical information, and to "enrich" the qualitative scenarios by showing trends and dynamics not anticipated by the storylines [31]. Schweizer and Kriegler criticise the assumption that models alone can ensure consistency of a scenario narrative [32]. The European Environment Agency recommend that integration is crucial in viewing future developments and is based on interdiscipliniarity, as a combination derived from the integration of multidisciplinary ideas or methods permitting explanation or assessment not achievable of non-integrated multidisciplinary ideas or tools [24]. 


\section{Working Paper}

Fig. 1. Schematic illustration of alternative scenario formulations, from narrative storylines to quantitative formal models

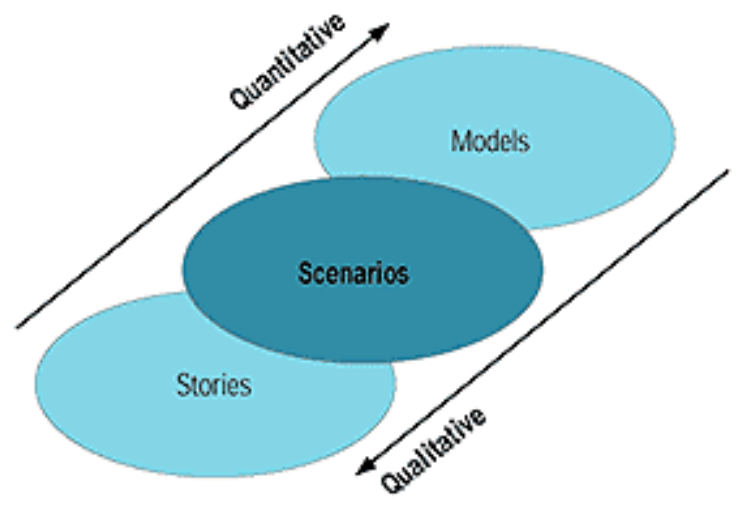

Source: Nakicenovic et al. (2000)

Each narrative scenario or storyline is a qualitative description of how key features diverge and are connected to each other (e.g. population growth, economic growth, technological development and policies). Depending on the logic of the scenario, certain developments are amplified or deemphasised. As a non-probabilistic assessment it does not present any of the scenarios as more or less likely. At a prominent level in methodological discussion, two approaches have been proposed to deal with uncertainty in scenario analysis; i) using narratives, and ii) using probabilistic approaches [33]. Using probabilistic assessment on scenarios can negate the benefit of using the technique by focussing attention on a single ‘likely’ future. The Joint Research Centre Institute for Prospective Technological Studies (JRC-IPTS) has advised against using probabilities [34], while Schnarrs and Ziamou state that most practitioners are against assigning probabilities as the "essence" of scenario analysis is to avoid false exactness [35]. Probabilistic approaches may imply a historical bias or determinism that does not evolve and may diverge or even bifurcate from historical 


\section{Working Paper}

trends. ${ }^{6}$ As discussed by Craig et al., most economic forecasting models embody historical dynamics through statistical relationships forecasted into the future [7].

\subsection{The evolution of dynamics}

The approaches to scenario analysis could be described as an inductive or bottom-up trends approach where scenarios emerge step by step from the data, and a deductive topdown approach where the scenario narrative is constructed from the framework devised to begin with [34]. Scenario themes describe the nature of variables, dynamics and interconnections through approaches such as actors, factors and sectors [37]. The dynamics explored may have considerable impact on future emissions based on their evolution and interaction occurring as events and processes, and are discernible in the system today. The interactions could be described as synergistic or emergent behaviour, where the complex combination of driving forces is greater than the sum of its parts. The use of 'exploratory scenarios' deliberately explores what might happen if the development of scenario driving forces were to take a particular direction in the future [17]. Exploratory scenarios look at structural uncertainty. A type of sensitivity analysis uses different combinations of input data in each scenario to explore data uncertainty. This potentially addresses an issue with optimising modelling for energy and emissions, which risk producing thinking entrenched in current dynamics of solutions, possibilities and limitations [17]. Lempert points to significant methodological issues with implications for energy and emissions modelling [38]. Due to deep uncertainty, the limitations of probability approaches and the multidimensional problem character, climate change is not even theoretically optimisable.

In the development of exploratory scenarios van Der Heijden [39] proposes linking historical and present events with hypothetical futures. Alcamo describes this as 'step-wise

\footnotetext{
${ }^{6}$ This problem can arise where there is a projection of past trends or the forecast of probable outcomes. The $\mathrm{OECD/}$ IEA discuss some of the limitations of purely quantitative approaches [36].
} 


\section{Working Paper}

changes' of driving forces, as the main factors that influence change [19]. In the quantitative process, values for these driving forces must be assumed by modellers or taken from other studies. For the purposes of emission scenarios, scenario driving forces are often defined by the Kaya identity $[40,41] .^{7}$

The "macro-bias" evident in many scenarios, occurs where scenarios excessively depend on macro-aspects (e.g. economic growth and oil price) [42]. The logics are top-down, with processes at meso and micro level determined by dominant macro dynamics affecting the system. A related problem is where the dynamic and outcome of scenarios are unsurprising and tautological [43]. In discussing these problems Elzen et al. [44] recommends incorporating sectoral dynamics for the inclusion of meso and micro dynamics, where different actor groups (e.g. firms, users, public authorities, universities) are involved in learning processes, social networks, lifestyles and worldviews. Hughes and Strachan proclaimed the importance of representing actors as sociotechnical changes are not brought about by disembodied high level trends or technical infrastructures, but by the decisions and actions of numerous actors [45]. An important insight from this methodological discussion is that actors can be reinforcing or conflicting. This is both an effective metaphor for the complexity of the system and also the problems with simple assumptions on consistency in scenarios.

\subsection{Scenario characteristics}

Given the diversity of fields now using scenarios, the processes, content and structure of scenarios developed vary significantly. Although scenario typologies are evolving [11, 17], there is no common theoretical and methodological framework for scenario analysis [25]. The characteristics of scenarios, the framework and process used and the form of the

\footnotetext{
${ }^{7}$ See section 3.6 for further discussion.
} 


\section{Working Paper}

scenarios are determined by the goals of the exercise [19]. Given the multitude of variations in scenario exercises it may be useful to clarify some scenario characteristics.

Various definitions of emission scenarios are present in the literature. A commonly used definition is that provided in the SRES [18]; as a plausible description of how the future may develop based on a coherent and internally consistent set of assumptions ("scenario logic") about key relationships and driving forces. A number of characteristics of "good" scenarios have been proposed by Alcamo [19];

i) firstly, that the scenarios fulfil the objectives of the exercise,

ii) are transparent and sufficiently documented to be understood,

iii) are plausible (or 'not implausible'),

iv) are internally consistent (can be shown by model),

v) challenge beliefs or broaden the understanding of decision-makers, and,

vi) are 'rich' to convey diverse information and provide insights into non-linear or interrupted trends.

The JRC-IPTS recommend five core criteria to guide the scenario process [34]:

i) Plausibility: The selected scenarios must be plausible, this means that they must fall within the limits of what might conceivably happen.

ii) Differentiation: they should be structurally different, meaning that they should not be so close to one another that they become simply variations of a base case. 


\section{Working Paper}

iii) Consistency: They must be internal consistent. The combination of logics in a scenario must not have any built-in inconsistency that would undermine the credibility of the scenario.

iv) Decision making utility: Each scenario, and all scenarios as a set, should contribute specific insights into the future that will allow on the decision focus that was selected.

v) Challenge: the scenarios should challenge the organisation's conventional wisdom about the future.

In contrast, van der Heijden [39] offers a looser interpretation and proposes the following criteria; to be plausible, consistent and give a relevant new perspective. van der Heiden proposes that apart from these general rules, the scenario planner has flexibility in deciding how to construct the scenarios and what organising principles to apply. While the guidance above implies key characteristics of robust scenarios, methodological issues remain. The nature of these issues is dependent on the objectives of the analysis.

Internal consistency within scenarios is an organising principle frequently stated in the scenarios literature. Mander et al. argue against the use of internal consistency within scenarios, proposing that consistency is not a consistent feature of society [46]. The cooccurrence of trend and counter-trend is a more consistent feature of complex societies than consistency itself. This aligns concepts with recognising the complexity of the anthropogenic system under investigation. The methodological requirements of logical causality and consistency may be limiting factors in this respect, as paradoxical simultaneous trends and counter-trends may emerge [47]. A number of potential responses to this issue are offered by the authors including using recombined trends and the quantitative approach of Lempert [48]. In general, the search for consistency as an organising principle is more relevant to 


\section{Working Paper}

exploratory and/or quantitative scenarios, with the prime aim of establishing a plausible range. Establishing consistency homogenises and helps to apply bounds to the stretching of the range, particularly where the extremes of the range are provided for by the scenario axes technique. If the higher priority of the study is to examine the complex interaction of driving forces, consistency becomes demoted as an organising principle, recognising inevitable inconsistencies in the real world. Inconsistency can be used to examine complex interaction of existing dynamics, or unfolding of potential new dynamics. New dynamics in the scenarios widen scope of results towards lower plausibility outcomes. This interplay of consistency and plausibility, and the method to resolve depends on the goals of the exercise. A relevant consideration is that the structured process of exploratory scenarios seeks to analyse but not predict complexity and uncertainty. By this, it gives a picture of alternative plausible developments that may not occur, but should cover the plausible range. This amounts to an approach to engaging with uncertainty, and given the conflicts, merits further research in the methodological literature. Inconsistency or unfolding of paradoxical developments is explored by Postma and Liebl through "inconsistency analysis" [47]. Weimer- Jehle proposed cross impact balances (CIB) for developing internally consistent qualitative scenarios [49]. Kemp-Benedict [50] echoes the aforementioned issue above of potentially incongruent scenario consistency and diversity by suggesting a combination of CIB with the scenario diversity analysis approach [51].

The issues of surprise, catastrophe and wildcards are important considerations that influence the range of "plausible" outcomes. Again the objectives of the scenario exercise dictate the approach. As prescribed in the SRES, the scenarios were not devised for contingency or emergency planning that includes wildcards or catastrophes. Plausibility is determined by the analysis of the historical and current situation, potential evolution of driving forces discerned from the literature and comparison with existing forecasts. Hence 


\section{Working Paper}

wildcards and catastrophes, and the strategic implications of these, are outside of the scope of such inquiry. This deliberate exclusion of low probability events and extremes places emphasis on mapping the range of "plausible futures". Schnarrs and Ziamou have advised against producing excessively wide spans for the scenarios, and therefore excluding extremes, as it is "too-safe" to look at wide spans [35]. While it increases the likelihood that the true future state will not be missed, scenarios with very wide spans of estimates may be less useful [27].

A distinction must be made between future-forward "exploratory scenarios" and future-backward "backcasting" or "anticipatory" scenarios [25, 19]. In descriptive exploratory scenarios the goal is open-ended exploration of alternative evolutions and not pathways to utopias or dystopias or what could be described as optimistic and pessimistic routes. This is the "neutral" objective of scenarios. Developments within the scenarios may be viewed as either positive or negative, depending on perspective. "Backcasting" scenarios are more normative and prescriptive by deliberately assigning a preferred future and working back to the present. A further distinction is made with baseline or non-intervention verses policy scenarios. Baseline scenarios explore evolution without additional energy and mitigation policies and measures (PAM's). PAM's may be tested using the baseline scenarios as part of mitigation analysis. The emerging complication is that even baseline emission scenarios must include at least some explicit energy and mitigation policies, particularly due to the Kyoto Protocol entering into force in 2005 [29].

Time scale is a key consideration in bounding the scope of the scenario exercise as is the spatial scale. The difficulties experienced with forecast accuracy previously described, suggests that it is useful to use exploratory scenarios even on short to medium-term time scales, particularly as short-term decisions have long term consequences. While a shorter 


\section{Working Paper}

time scale may reduce the possibility for analysing radical shifts, longer time scales can reduce policy relevance [24].

It has been recommended not to develop new scenarios unless it is necessary [19]. There is voluminous forecast and scenario data at the global and regional level from the SRES process. However, due to the homogenous and long term nature of global scenarios the utility of down-scaling this information could be questioned. Two national examples of downscaling include Trefers et al. [52] and Kaivo-oja et al. [53], where both of these exercises specifically benefitted from using existing scenarios. The Dutch energy scenarios to 2050 of Trefers et al. [52] were based around using just two of the SRES scenarios namely $\mathrm{A} 1(\mathrm{~B})$ and $\mathrm{B} 2$. This process was chosen on a longer time scale as they were back-casting scenarios. Kaivo-oja et al. also used the SRES scenarios given their importance in the climate policy discourse of most countries. In that sense operationalising the SRES scenarios yielded policy insights in its own right. Nevertheless, using existing scenarios can also act as a straitjacket, both when downscaling and quantifying [54]. The divergent reality at the national level has been documented where different future scenarios for one member state may show quite diverging energy images [55].

\subsection{Identifying and exploring scenario driving forces}

The European Environment Agency, illustrate how driving forces will be differently identified and discussed depending on the aims of the study [56]. Trajectories of future energy carbon emission are determined by complex dynamics [29]. They can be expressed as driving forces including demographics, economics, resources, technology and non-climate policies [18]. Scenario techniques proposed in the literature are often structured on ordering and ranking systems for driving forces [36, 57]. The conception of the SRES [18] as the seminal literature in the field is based on the Kaya identity [40]. Rather than using a ranking 


\section{Working Paper}

system, the SRES explores the potential evolution and interaction of scenario driving forces through two modes. These involve understanding the historical and current situation and existing quantitative scenarios and forecasts and also the potential interactions of the development of driving forces. The Kaya identity provides the framework to explore and discuss scenario driving forces, as the basic entities of scenario development in both the qualitative narratives and their quantitative representation.

A framework often used to describe changes in an environmental impact is the IPAT identity $[58,59]$. The IPAT identity relates impacts (I) to population (P) multiplied by affluence (A) and technology (T);

Impact $=$ Population X Affluence X Technology.

The IPAT identity has often been referred to as the 'Kaya identity' as a specific application of IPAT used in emission scenarios. In function 2 it multiplies population growth, per capita gross domestic product (GDP), energy consumption per unit GDP, and emissions per unit energy on one side of the identity, with total $\mathrm{CO}_{2}$ emissions represented on the other side [40, 41].

$\mathrm{CO}_{2}$ Emissions $=$ Population $\mathrm{X}(\mathrm{GDP} /$ Population $) \mathrm{X}($ Energy/ GDP $) \mathrm{X}\left(\mathrm{CO}_{2} /\right.$ Energy $)$

The Kaya multiplicative identity presents much utility as it can be further decomposed into other effects [60], but it does not suggest direct causality. Some important caveats to the use of the Kaya identity are noted by Nakicenovic et al. [18]. The four terms on the right-hand side of equation should not be considered as fundamental driving forces in themselves, nor should they be considered as generally independent of each other. While the identity may 


\section{Working Paper}

imply a linear increase in emissions, e.g. with an increase in population, this depends on the interactions and relationships between driving forces.

The SRES structured the exploration of scenario driving forces and interactions, and consequently the literature review, using the following framework related to the Kaya identity;

1. Population

2. Economic and social development

3. Energy resources and technology

4. Agriculture, forestry and land-use change

5. Other sources of non- $\mathrm{CO}_{2}$ GHG's

6. Non-climate policies

Specifically with application to energy and related emissions the following framework for identification and discussion of driving forces is now proposed;

1. Population

2. Economic and social development

3. Energy resources and technology

4. Governance and policies

Agriculture, forestry and land-use change and also non- $\mathrm{CO}_{2}$ GHG's are omitted as they are not directly relevant to energy $\mathrm{CO}_{2}$ scenarios. Meanwhile, "policies" has been modified to "Governance, and policies" as an alternative categorisation. This is in keeping with the six sector approach to scenarios $[61,62]$. This heading also reflects an evolving discourse with 


\section{Working Paper}

implications for the development path encompassing a variety of levels of governance and institutional aspects [63]. "Policies" includes the mitigation and energy policies implemented and legislatively provided for by the base year of the analysis.

\subsection{Scenario development}

The scenario axes technique is often recommended as a useful tool to construct images of the future [39] as an approach to structuring thinking. This technique functions by the identification of the two most important driving forces by characterisations such as uncertainty and impact. Through the selection of two-dimensional axes which form the four scenario quadrants in Fig. 2 these uncertainties characterise the main differences between alternative scenarios. Using the unifying structure of the scenario axes, the scenarios are developed as alternate stories of how the future may unfold. This development is reasoned from the position of the scenarios on the axes, the logic of internal consistency and based on a cause and effect logic [64].

Fig. 2. Scenario axes leading to alternative scenarios

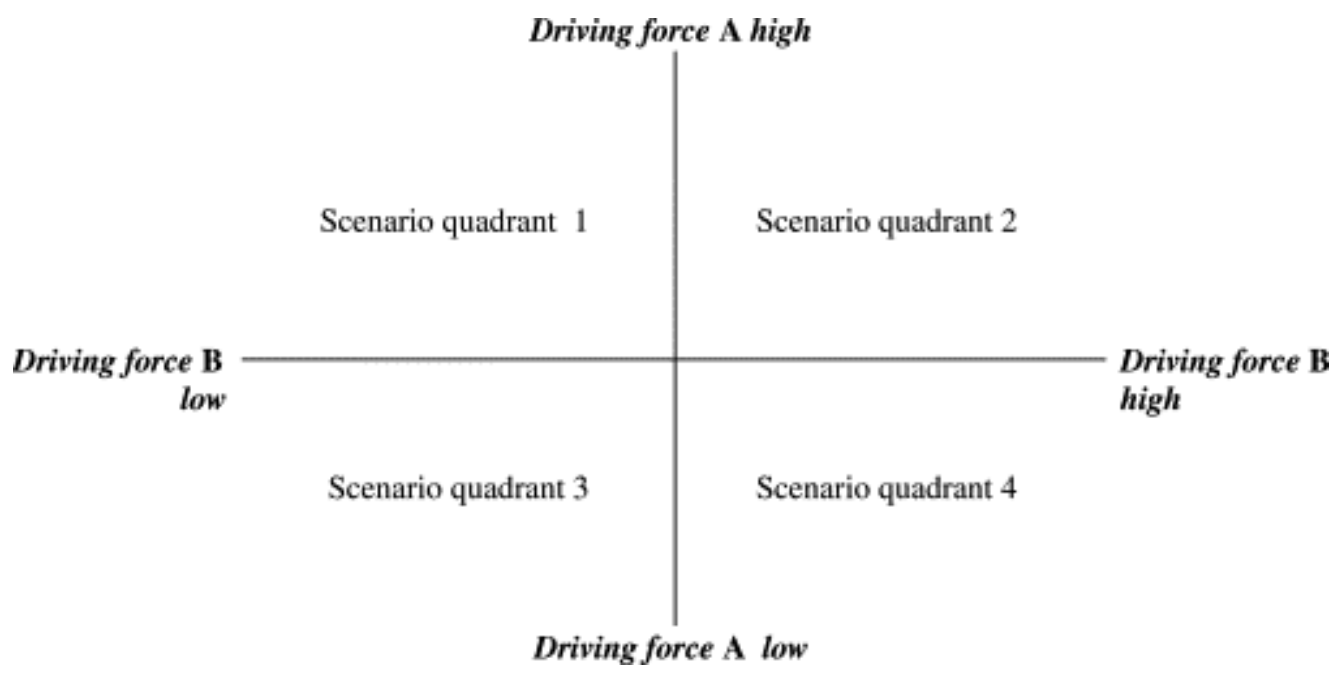

Source: Van 't Klooster and van Asselt (2005) 


\section{Working Paper}

This approach can be theoretically problematic and potentially constraining to creative thinking [46]. The axes are a framework to structure thinking on the future. To prevent the development of ad-hoc, arbitrary, implausible or illogical futures they require further consideration of the development and interaction of other driving forces. The consideration of uncertainty in the development of other driving forces can be arrived at through the structured analysis based on the Kaya identity. The combination of driving forces within each scenario can therefore be varied to encompass a rich pluralistic multidimensional conception of the future. The scenario axes should be viewed with caution as a structural tool, and not viewed as a rigid blueprint or "straitjacket" [64]. In responding to this challenge, examples of alternative applications of scenario axes include Natural Resources Canada [65] illustrating three dimensional axes in Fig. 3. The SRES used a two dimensional framework but also illustrates the input of other driving forces in Fig. 4

Fig. 3. Canada energy technology futures scenario schematic

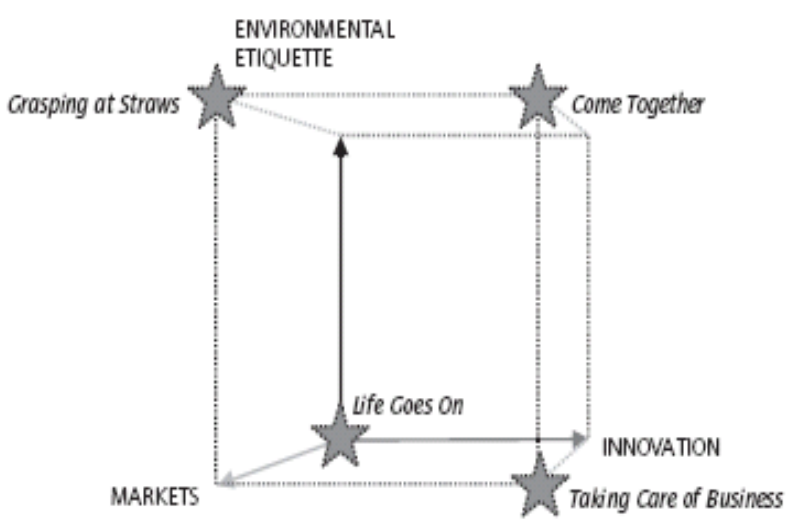

Source: Natural Resources Canada (2000)

Fig. 4. SRES scenario schematic 


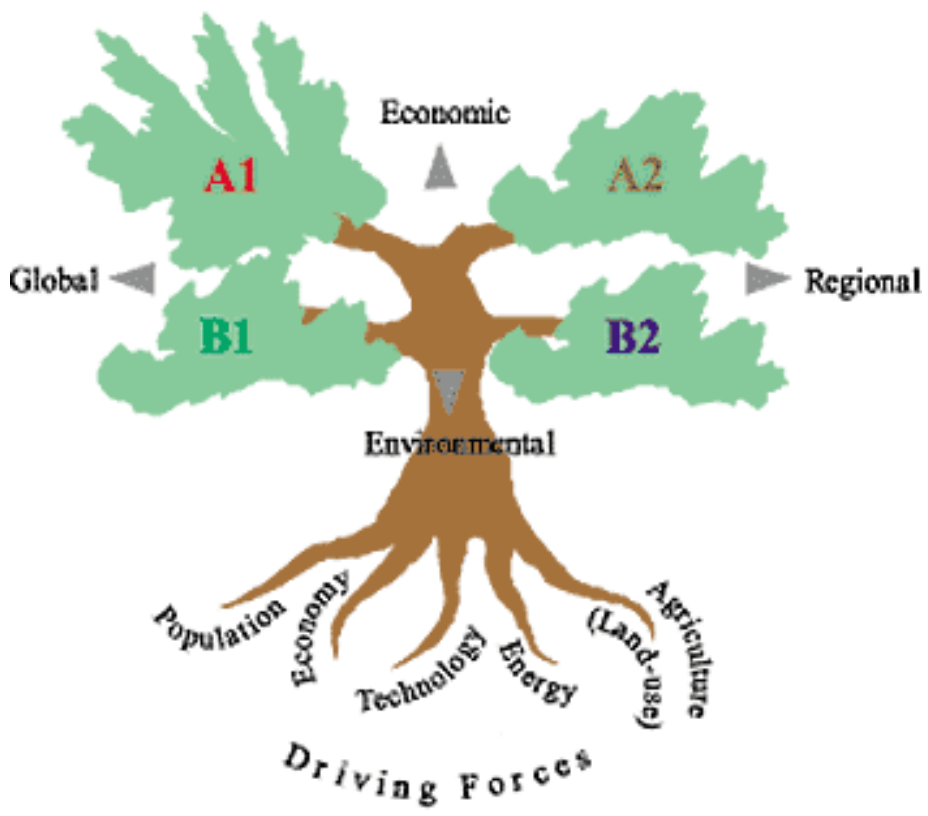

Source: Nakicenovic et al. (2000)

While 'macro' or global and regional developments can have a considerable impact at a national level, two potential approaches are available: i) explicitly consider the potential evolution of macro developments as part of the exercise, or, ii) assume that macro developments evolve in logical consistency with the driving forces in the national scenarios. Baseline scenarios will exclude further policy developments under the UNFCCC process or other intergovernmental levels such as the European Union (EU). The ordering of driving forces through themes and trends within the scenarios is achieved using the logics provided by the axes and exploration of the other driving forces. It can be illustrated by a table of change in key variables or 'futures table' [2], documenting key assumptions [22] or the main features of scenario development paths [53]. These lead to the draft narratives that inform the quantitative modelling process. The attendant multidimensionality is illustrated by the roots of the tree in Fig. 4.

The number of scenarios to be developed in the research is a key question in addressing the range of plausible futures. There has been a prevalence of three scenario 


\section{Working Paper}

exercises, while four and five scenario exercises have begun to replace this approach [35]. This helps to avoid best case, worst case and middle case assumptions which are contrary to exploratory scenarios, as they may or may not be equally likely. As proposed in Nakicenovic et al. [18] applying the principle of "Occam's razor" led the SRES to use the minimum number of scenarios adequate for assessment, with four storylines avoiding the central or most likely impression. No one scenario can encompass the possibility envelope and reflect the uncertainty in development pathways. More than two scenarios are required to illustrate that the future depends on many different underlying dynamics. Avoiding three prevents the impression that there is a central or most likely future. Using four scenarios addresses these concerns although it can raise communication issues [19].

The narrative storylines in exploratory scenarios have two core functions; aiding exploration and also communication. They are stylised narrative descriptions of alternative future developments relevant to the research question and further guidance is provided by [51]. The narratives can be from paragraphs to a few pages in length [36]. Elaborate plots and highly descriptive titles can be used to aid communication. Where they may appear idiosyncratic and arbitrary this stylistic approach requires consideration once more of the audience and the goals of the exercise.

\subsection{Process of inquiry}

The scenario typology of Borjeson et al. [17] describes a number of techniques that can be employed in the process of scenario development to contribute to the "generating phase" for generating and collecting ideas, knowledge and views regarding some part of the future. In exploratory scenarios these include workshops, survey and Delphi methods. Stewart claimed that the Delphi technique was created and continues to be employed as it is a cheap and quick way of getting the information needed for making decisions [67]. Stewart proposed that it is used when there is a shortage of data, inadequate models and lack of time 


\section{Working Paper}

or resources to make a thorough scientific study. It is important to note that a reliance on expert opinion and workshops may also constrain analysis given the poorly understood issues often the subject of scenario exercises, and the inability of participants to perceive their own assumptions [68] a common problem with all foresight techniques [51]. It may be desirable to use participation in scenarios, from both the scientific inquiry and democracy standpoints as both potentially benefit from inclusion of diverse perspectives. Nevertheless, it is ultimately the design, application and approach to the process that delivers diverse, robust scenarios. An alternative approach described by Borjeson et al. [17] is an internal scenario project, where one researcher, a group of researchers or a scenario project team produce the scenarios backoffice as applied in recent studies $[1,70,71]$. Such a process is usually less time and resource intensive but caution is once more required. There is potential for bias and limited worldviews as the judgement of a number of informed people is potentially better than the judgement of a single individual [72]. The difficulty in defining concepts and methodologies for inquiry using the scenario approach has been criticised [73]. The distinct variations in application are an inevitable result of the multifarious issue domains of scenarios. Specifically within the environmental and energy domain the Storyline and Simulation (SAS) approach of Alcamo [19] has emerged as a common basis [72].

The needs of energy planning and mitigation policy have driven the development and application of a plethora of modeling tools and techniques for quantification [74, 75, 29, 76]. Energy policy is typically informed by reference to analytical models, but variations in approaches require considerable filtration and translation in order to appropriately inform design and implementation of government policy [76]. Interestingly, a key conclusion of Armstrong [77] offered that simple models can yield results as accurate as more complicated techniques, and in response Craig et al. [7] concluded that accurate data and careful scenario creation are more important. In more general terms, de Jounvenel [78] proposed that 


\section{Working Paper}

simulation models based on observations of the past are favoured by economists, econometrists, statisticians and forecasters. Subject to the GIGO effect, ${ }^{8}$ the accuracy or scientific quality of forecasts is not guaranteed where results may be arbitrary and subjective. According to de Jouvenel, these methods have long been opposed to the scenario method, which is more developed and used by futurists [78]. An additional problem is that technological and economic realities are implicitly embedded in energy modelling apparatus while results are often promoted as "objective" [25]. Midttun and Baumgartner termed this combination of modelling and politics as "the scientific negotiation of energy futures" [79]. It increases the need for not only reproducible results and published models, but transparent assumptions and dynamics in energy and emissions modelling studies. Forecasts can hence embody an inexplicit worldview and value system hidden in model architecture and assumptions. It is not only an ethical and political issue, but as assumed human factors can change it is also an issue of uncertainty and consequent difficulty for forecasting.

\section{Case study of short term scenarios for Ireland}

The Irish context is an interesting example of the difficulties in forecasting national energy and emissions in the short term. In evaluating the Gothenburg Protocol, Kelly et al. [80] stated that the forecast used for Gothenburg in 1999 had underestimated Ireland's energy use in 2010 by $11 \% .^{9}$ The population, economic and mobility activity leading to this growth were all underestimated. The authors concluded that rates of technological and behavioural change would be important factors in future modelling. The "Energy 2000" study of the European Community in 1985 underestimated Ireland's consumption of oil and gas and

\footnotetext{
${ }^{8}$ Garbage In Garbage Out.

${ }^{9}$ In this context, the potential significance of such underestimations is not just for environmental protection in meeting air quality targets but also in arenas such as cost effectiveness and cost benefit analysis of measures to meet targets.
} 


\section{Working Paper}

overestimated solid fuels and renewable energy in 2000 [81]. This study found substantial forecast error over the EU and outlined three areas of uncertainty; unanticipated "strong" political decisions, ${ }^{10}$ unanticipated energy requirements ${ }^{11}$ and data definition and availability. The recession in Ireland has further highlighted accuracy difficulties, with errors of up to 9.1\% for the first forecast year in energy $\mathrm{CO}_{2}$ forecasts [82]. The reviews of Irelands' communications to the UNFCCC noted a significant difference between recent short term projections and requested explanation $[83,84]$.

The scenario development process detailed below is applicable for use with other quantitative modeling techniques as per SAS. The quantitative technique applied in [1] for short term carbon emission scenarios for Ireland was index decomposition analysis (IDA), specifically an application of the Log Mean Divisia Index (LMDI I) of Ang and Liu [85]. This multi-sectoral decomposition framework was used for historical analysis and quantitative scenario development ${ }^{12}$. IDA is widely used for historical emission and energy analysis, but has rarely been used in conjunction with scenario techniques or in forecasting. This has been recommended as a key area for future research $[87,88,89]$. Recent studies have used different combinations of scenario approaches and IDA [90, 91, 69, 92]. Agnolucci et al. [91] used the back-casting scenario approach with the Kaya identity [40] to elaborate different UK carbon reduction scenarios to 2050. These back-casting scenarios were both qualitative and quantitative, using an expert knowledge approach to model variables. The other studies were trend-based scenarios using IPAT, Laspeyres or divisia decomposition. In contrast, [1] applied exploratory rather than trend based scenarios cognisant of, but not relying on historical dynamics.

\footnotetext{
${ }^{10}$ These decisions included those from increasing concerns of climate change and the introduction of feed-in tariffs in Germany.

${ }^{11}$ Including increased transport activity and the shift to gas.

${ }^{12}$ See [93] for specific details on the decomposition technique applied.
} 


\section{Working Paper}

Following the methodological guidance provided in the literature as previously described, the process applied for scenario development in [1] was towards the construction of hybrid exploratory scenarios for short term national energy-related carbon emissions to 2020. These baseline emission scenarios are a potential response to issues of forecast accuracy and uncertainty, encapsulating equally plausible alternative development pathways and consequent emission trajectories under 'baseline' no change in energy and mitigation policy. Such hybrid qualitative and quantitative scenarios permit the articulation of integrated development paths as described by Sathaye et al. [63] and include a complex array of technological, economic, social, governance and cultural characteristics. The process applied is similar to the SAS approach of Alcamo [19] and could be summarised in the following broad stages in Fig. 5;

Fig. 5. Stages in the development process for short term hybrid scenarios 


\section{Working Paper}

1. Identify research question

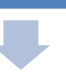

2. Identify data requirements and collection

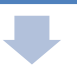

3. Conduct quantitative historical analysis

مَ

4. Identify scenario driving forces

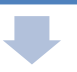

5. Explore the development of driving forces and interactions

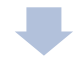

6. Select scenario axes and logics of multiple driving forces

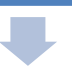

7. Construct draft qualitative scenario narratives

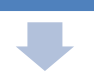

8. Select rates of change in model variables

\section{I}

9. Apply evolution from quantitative model base year to horizon year

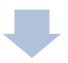

10. Graph and present quantitative estimates of emissions

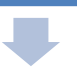

11. Explore plausibility and internal consistency

ปे
$\frac{1}{d}$
$\frac{ \pm}{\omega}$
$\frac{1}{0}$
0

12. Finalise integrated qualitative and quantitative scenarios

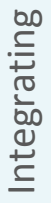




\section{Working Paper}

The flow diagram in Fig. 5 illustrates the process of scenario development characterised broadly on the right hand side through the phases of the scenario typology of [17]. Stages 1 to 5 involve the "generation of ideas," towards the development of the scenarios. Stage 1 dictates the scope of the scenario exercise. Stages 2-5 discern the historical and current situation and explore the potential evolution and interaction of driving forces affecting its plausible future development. Stages 6 to 10 involve the "integration" of qualitative and quantitative scenario components into a whole leading to the development of qualitative narratives of scenario evolution and a quantitative mathematical representation through the chosen model, in this case IDA, described as a divisia index scenario generator (DISCGEN). Stages 11 to 12 are the "checking" phase where logical causality, plausibility and consistency are considered leading to iterative amendments. Evaluation of scenarios and comparison with carbon emission forecasts for Ireland existing at the time of the study are available in [1].

\section{Concluding remarks}

Evidence from the literature on the accuracy of quantitative point forecasts of energy and emissions suggests that uncertainty is endemic even on short and medium term time scales. It leads to considerable difficulties in producing accurate forecasts [3]. Point forecasts are essentially obligatory in the context of UNFCCC requirements but this approach is counter-productive to effective analysis and creates strategic difficulties for policy and decision-making. It may be prudent for the UNFCCC to reconsider the recommended approach in the reporting guidelines [10].

The technique of scenario analysis is increasingly applied in scientific inquiry of energy and emissions on long time-scales but evidence suggests its utility in the short term. In exploring short-to-medium term change, scenarios have a utility in exploring baseline 


\section{Working Paper}

quantification in addition to assessing policy effects. Grunwald [94] stated that studies of energy futures, including model based, are inevitably social constructs subject to arbitrariness and ideology necessitating transparency and debate. The argument for plural, interdisciplinary and varied conceptions of the future is strong both in scientific inquiry to aid analysis and in decision-making to aid strategy and participative democracy. Scenarios structure thinking on the future, bound uncertainty on future evolution and can be used to document important assumptions.

There is no common framework for scenario analysis due to the breadth if its application. Scenarios are constructed based on research objectives and use a range of scenario characteristics for guidance, with the SAS approach emerging as a common thread for the environment [72]. At the frontier of scenarios research in engaging with uncertainty, integrated or 'hybrid' qualitative and quantitative techniques that incorporate an interdisciplinary approach have advantages. Integration can be achieved through a framework of axes and logics to structure scenario driving forces within scenario narratives which also aid communication. Narratives provide input to the selection and checking of appropriate numerical estimates of driving force change in quantification in a process similar to Alcamo [19]. Narratives also permit the enhanced exploration of 'softer' issues in development paths such as governance, institutions and values which are outside of the scope of quantitative approaches but are ultimately crucial to outcomes.

No credible analysis should rely on just one or two forecasts, careful scenario creation is more important than complex modelling [7], and simple models can yield results as accurate as more complicated techniques [77]. While the statistical dispersion of results is theoretically less in the short term, the complexity of human influenced systems is irreducible and omnipresent, and ex-post analysis shows that the system confounds prediction. An optimal approach would involve exploring and preparing for equally plausible futures which 


\section{Working Paper}

is better facilitated by exploratory scenarios than BAU projections. Given the domination of quantitative point forecasts for shorter term insights, despite a poor record of accuracy and other issues, further methodological research is merited on the use of scenario techniques for this purpose. In a business environment, Onkal et al. [8] looked at the effectiveness of scenarios in channeling forecast advice. In a policy issue of great import such as energy and emissions, the capacity of the approach to enhance decision-making requires further scholarship.

Separate to these methodological and praxis issues, from a policy perspective Sathaye et al. [63] concluded reducing emissions is not simply a question of mitigation or energy policy, but is inherently linked to the underlying wider development path. The advancement of more broad holistic perspectives on development and processes of change is consequently policy relevant in all states, for which purpose integrated scenarios are an ideal tool. A common set of short term national scenarios informing related foresight tasks such as economic forecasts, population projections and environmental, technology and social analysis could have many benefits. It could aid in addressing similar confounding uncertainties encountered across these related fields [1] and facilitate a common language for analysts. It could also operate as a mode of mainstreaming sustainable development and mitigation across policy functions. By using a common set of scenarios, various disparate planning and policy functions could be integrated from economic, transport and spatial development planning to environmental and social policies. Whole-of-government decision-making is essential to capturing policy synergies, coalition building, political leadership, integrated approaches and policy coherence [63] and ultimately cost and environmentally effective mitigation.

\section{Acknowledgements}




\section{Working Paper}

The original research that facilitated this paper was part-funded by scholarship from the Irish Research Council for Humanities and Social Sciences and the Dublin Institute of Technology ABBEST scheme. These schemes were solely involved in the research in a funding and administrative capacity.

\section{References}

[1] Author, 2010.

[2] V., Varho, P., Tapio, Combining the qualitative and quantitative with the Q2 scenario technique - The case of transport and climate, Technol Forecast Soc, 804 (2013), 611-630.

[3] H. Linderoth, Forecast errors in IEA-countries' energy consumption, Energ Policy 30 (2002) 53-61.

[4] J.J. Winebrake, D. Sakva, An evaluation of errors in US energy forecasts: 1982-2003. Energ Policy 34 (2006) 3475-3483.

[5] B.C. O' Neill, M. Desai, Accuracy of past projections of US energy consumption, Energ Policy 33 8, (2005) 979-993.

[6] UNFCCC, 2004: Report on the workshop on the preparation of fourth national communications from Parties included in Annex I to the Convention. Note by the secretariat. United Nations Framework Convention on Climate Change, (FCCC/SBI/2004/INF.14). <http://unfccc.int/resource/docs/2004/sbi/inf14.pdf> Accessed 1 March, 2010.

[7] P.P. Craig, A. Gadgil, J.G. Koomey, What can history teach us? A retrospective examination of long-term energy forecasts for the United States, Annu Rev Energ Env 27 (2002) 83-118. 


\section{Working Paper}

[8] D. Önkal, K.Z. Sayım, S.G. Mustafa, Scenarios as channels of forecast advice, Technol Forecast Soc 80 (2013) 772-788.

[9] R.B. Mitchell, W.C. Clark, D.W. Cash, N.M. Dickson, (ed) Global Environmental Assessments: Information and Influence, Cambridge, MA: MIT Press, 2006.

[10] UNFCCC, Review of the implementation of commitments and of the other provisions of the Convention. United Nations Framework Convention on Climate Change guidelines on reporting and review. Conference Of the Parties, Fifth session, Bonn, 25 October - 5 November 1999, Agenda items 4 (a) and 4 (h), 2000. $<$ http://unfccc.int/resource/docs/cop5/07.pdf>, accessed 29 March 2011.

[11] P.J. Van Notten, M. Rotmans, M. van Asselt, D. S. Rothman, An updated scenario typology, Futures 355 (2003) 423-443.

[12] P. Raskin, F. Monks, T. Ribeiro, D. van Vuuren, M. Zurek, A.A. Concheiro, C. Field, Global Scenarios in Historical Perspective. In Ecosystems and Human Well-Being: Scenarios - Findings of the Scenarios Working Group Millennium Ecosystem Assessment Series, edited by Steve Carpenter, Prabhu Pingali, Elena Bennett, and Monika Zurek, Washington, DC: Island Press, 2005, 35-44. http://www.maweb.org/documents/document.326.aspx.pdf

[13] R. Bradfield, G. Wright, G. Burt, G. Cairns, K. van der Heijden, The origins and evolution of scenario techniques in long range business planning, Futures 37 (2005) $795-812$

[14] R. Silberglitt, A. Hove, P. Shulman, Analysis of US energy scenarios: Meta-scenarios, pathways, and policy implications, Technol Forecast Soc 70 4, (2003) 297-315.

[15] J. Alcamo, (ed.) Environmental Futures. The practice of environmental scenario analysis. Developments in Integrated Environmental Assessment 2. Elsevier, Amsterdam, the Netherlands, 2008, 197. 


\section{Working Paper}

[16] O' Brien, F.A. Scenario planning-lessons for practice from teaching and learning, Eur J Oper Res 1523 (2004) 709-722.

[17] L. Börjeson, M. Höjer, K. Dreborg, T. Ekvall, G. Finnveden, Scenario types and techniques: towards a user's guide, Futures 38 (2006) 723-739.

[18] N. Nakicenovic, J. Alcamo, G. Davis, B. de Vries, J. Fenham, S. Gaffin, K. Gregory, A. Grübler, T.-Y. Jung, T. Kram, E.L. La Rovere, L. Michaelis, S. Mori, T. Morita, W. Pepper, H. Pitcher, L. Price, K. Riahi, A. Reohrl, H.H. Rogner, A. Sankovski, M. Schlesinger, P. Shukla, S. Smith, R. Swart, S. van Rooijen, N. Victor, and Z. Dadi, 2000: Special report on emissions scenarios. Working Group III, Intergovernmental Panel on Climate Change, Cambridge University Press, Cambridge, 2000, pp. 595.

[19] J. Alcamo, Scenarios as Tools for International Environmental Assessments. Environmental Issue Report No. 24, European Environment Agency, 2001.

[20] H.H. Holmes, Interpreting global energy and emission scenarios: methods for understanding and communicating policy insights, Doctoral dissertation, Stanford University, 2007. <http://www.holmeshummel.net/Dissertation.htm> Accessed 4 January 2010.

[21] P. Raskin, E. Kemp-Benedict, GEO Scenario Framework Background Paper for UNEP's Third Global Environmental Outlook Report, UNEP, Nairobi, 2002.

[22] R. Ghandan, J.G. Koomey, Using energy scenarios to explore alternative energy pathways in California. Energ Policy 33 (2005) 1117-1142.

[23] UNDP, UNDESA, WEC, World Energy Assessment: Energy and the Challenge of Sustainability, United Nations Development Programme, United Nations Department of Economic and Social Affairs, World Energy Council, New York, 2002. 


\section{Working Paper}

[24] European Environment Agency, Cloudy Crystal Balls. European Environment Agency, Environmental Issue Report no. 17, European Environment Agency, Copenhagen, Denmark, 2000.

[25] S.K. Nielsen, K. Karlsson, Energy scenarios: a review of methods, uses and suggestions for improvement: Int J Global Energy 273 (2007).

[26] V. Smil, Energy at the Crossroads, MIT Press, Cambridge, MA, 2003.

[27] M.B.A. van Asselt, Perspectives on uncertainty and risk: the PRIMA approach to decision-support. PhD-thesis, Kluwer Academics Publishers, Dordrecht, The Netherlands, 2000.

[28] R.J. Swart, P. Raskin, J. Robinson, The problem of the future: sustainability science and scenario analysis. Global Environ Chang 14 (2004) 137-146.

[29] B.S. Fisher, N. Nakicenovic, K. Alfsen, J. Corfee Morlot, F. de la Chesnaye, J.-Ch. Hourcade, K. Jiang, M. Kainuma, E. La Rovere, A. Matysek, A. Rana, K. Riahi, R. Richels, S. Rose, D. van Vuuren, R. Warren, Issues related to mitigation in the long term context, In Climate Change 2007: Mitigation. Contribution of Working Group III to the Fourth Assessment Report of the Inter-governmental Panel on Climate Change [B. Metz, O.R. Davidson, P.R. Bosch, R. Dave, L.A. Meyer (eds)], Cambridge University Press, Cambridge, United kingdom, 2007.

[30] T. Morita, J. Robinson, A. Adegbulugbe, J. Alcamo, D. Herbert, E.L. La Rovere, N. Nakicenovic, H. Pitcher, P. Raskin, K. Riahi, A. Sankovski, V. Sokolov, H.J.M. Vries, Z. Dadi, Greenhouse Gas Emission Mitigation Scenarios and Implications. In: B. Metz, O. Davidson, R. Swart J. Pan (eds.), 2001, Climate Change 2001: Mitigation, Contribution of Working Group III to the Third Assessment Report of the Intergovernmental Panel on Climate Change, Cambridge University Press, Cambridge, UK, 2001, pp. 700. 


\section{Working Paper}

[31] J. Alcamo, D. van Vuuren, C. Ringler, J. Alder, E. Bennett, D. Lodge, T. Masui, T., Morita, M. Rosegrant, O. Sala, K. Schulze, M. Zurek, B. Eickhout, M. Maerker, K. Kok, A.A. Concheiro, Y. Matsuoka, A. Hammon, Methodology for Developing the MA Scenarios, in Millenium Ecosystem Assessment Series, Ecosystems and Human Well-Being, Volume 2. Scenarios, Chapter 6, Island Press, 2005.

[32] V.J. Schweizer, E. Kriegler, Improving environmental change research with systematic techniquesfor qualitative scenarios. Environ Res Lett 7 (2012) 044011.

[33] IPCC, Meeting report workshop on new emission scenarios. Intergovernmental Panel on Climate Change, 29 June - 1 July 2005. Laxenburg, Austria. IPCC Working Group III Technical Support Unit, RIVM, Bilthoven, The Netherlands, 2005.

[34] JRC-IPTS, Forlearn: Online Foresight Guide. European Commission Joint Research Centre/ Institute for Prospective Technological Studies, 2008. <http://forlearn.jrc.ec.europa.eu/guide/0_home/index.htm> Accessed 3 January 2010.

[35] S. Schnaars, P.L. Ziamou, The essentials of scenario writing. Business Horizons 444 (2001) 25-31.

[36] OECD/ IEA, Energy to 2050 Scenarios for a sustainable future. International Energy Agency, Paris, France 2003.

[37] J. Rotmans, M. van Asselt, C. Anastasi, S. Greeuw, J. Mellors, S. Peters, D. Rothman, N. Rijkens, Visions for a sustainable Europe. Futures 32 (2000) 809831.

[38] Lempert, R., Nakicenovic, N., Sarewitz, D. and Schlesinger, M., Characterizing climatechange uncertainties for decision-makers. Climatic Change 65 (2004) 19.

[39] K. van der Heijden, Scenarios. The Art of Strategic Conversation, Wiley, Chichester, 1996. 


\section{Working Paper}

[40] Y. Kaya, Impact of Carbon Dioxide Emission Control on GNP Growth: Interpretation of Proposed Scenarios. Paper presented to the IPCC Energy and Industry Subgroup, Response Strategies Working Group, Paris, (mimeo), 1990.

[41] K. Yamaji, R. Matsuhashi, Y. Nagata, Y. Kaya, An Integrated Systems for $\mathrm{CO}_{2} /$ Energy/ GNP Analysis: Case Studies on Economic Measures for $\mathrm{CO}_{2}$ Reduction in Japan. Workshop on $\mathrm{CO}_{2}$ Reduction and Removal: Measures for the Next Century, 19-21 March 1991. International Institute for Applied Systems Analysis, Laxenburg, Austria, 1991.

[42] F.W. Geels, Towards sociotechnical scenarios and reflexive anticipation: Using patterns and regularities in technology dynamics, Williams, R. and Sorensen, K., (editors), Shaping Technology, Guiding Policy: Concepts, Spaces and Tools. Edward Elgar, 2002, pp. 355-381.

[43] I.J. Schoonenboom, H.C. Van Latensteijn, Toekomstonderzoek en beleid:Goede intenties en kwade kansen, in: Toekomstonderzoek en strategische beleidsvorming: Probleemverkenningen en praktijktoepassingen, Report from NRLO, no. 3, Nationale Raad voor Landbouwkundig Onderzoek, The Hague, 1997, pp. 924.

[44] B., Elzen, F. Geels, P.S. Hofman, K. Green, Socio-Technical Scenarios as a tool for Transition Policy. An example from the traffic and transport domain', Twente Workshop "Transitions to Sustainability through System Innovations" Enschede 2002.

[45] N. Hughes, N., Strachan, Methodological review of UK and international low carbon scenarios. Energ Policy 38 (2010) 6056-6065.

[46]S. L. Mander, A. Bows, K. L. Anderson, S. Shackley, P. Agnolucci, P. Ekins, The Tyndall decarbonisation scenarios-Part I: Development of a backcasting methodology with stakeholder participation. Energ Policy 3610 (2008) 37543763 


\section{Working Paper}

[47] T.J.B.M. Postma, F. Liebl, How to improve scenario analysis as a strategic management tool? Technol Forecast Soc 72 2, (2005) 161-173.

[48] R.J. Lempert, S. W. Popper, S. C. Bankes, Shaping the Next One Hundred Years: New Methods for Quantitative, Long-Term Policy Analysis, RAND, MR-1626-RPC, 2003.

[49] W. Weimer-Jehle, Cross-impact balances: a system-theoretical approach to crossimpact analysis, Technol Forecast Soc 73 (2006) 334-361

[50] E. Kemp-Benedict, Telling better stories: strengthening the story in story and simulation. Environ Res Lett 7 (2012) 041004.

[51] H. Carlsen, Climate change and the construction of scenario sets that span the range of societal uncertainties. Paper for International Studies Association Annual Convention 2009 (New York City, February).

[52] Treffers, D.J., Faaij, A.P.C., Spakman, J. and Seebregts, A., Exploring the possibility for setting up sustainable energy systems for long term: two visions for the Dutch energy system in 2050. Energ Policy 33 (2005) 1723-1743.

[53] J. Kaivo-oja, J. Luukkanen, M. Wilenius, Defining alternative national-scale socioeconomic and technological futures up to 2100: SRES scenarios for the case of Finland. Boreal Environ Res 9 (2004) 109125.

[54] K. Kok, D.S. Rothman, M. Patel, Multi-scale narratives from and IA perspective: Part 1. European and Mediterranean scenario development, Futures 38, (2006) 261-284

[55] M.J.J. Scheepers, A.J. Seebregts, J.J. Jong, J.M. de Maters, EU Standards for Energy Security of Supply - Updates on the Crisis Capability Index and the Supply/Demand Index Quantification for EU-27. ECN Beleidsstudies, 2006.

[56] European Environment Agency, The ShAIR scenario: Towards air and climate change outlooks, integrated assessment methodologies and tools applied to air pollution and 


\section{Working Paper}

greenhouse gases. Topic report 12/2001. European Environment Agency, Copenhagen, Denmark 2002.

[57] P. Schwartz, The Art of the Long View, Doubleday Currency, London, 1991.

[58] J.P. Holdren, Environmental degradation: population, affluence, technology, and sociopolitical factors. Environment 426 (2000) 4-5.

[59] P.R. Ehrlich, J.P. Holdren, Impact of population growth. Science 1713977 (1971) 1212 1217.

[60] Author, 2013.

[61] H. de Jouvenel, Prospective for a new citizenship. Futures 182 (1986) 12533.

[62] Kelly, R., Sirr, L., Ratcliffe, J., Futures Thinking to Achieve Sustainable Development at Local Level in Ireland. Foresight 62 (2004).

[63] J. Sathaye, A. Najam, C. Cocklin, T. Heller, F. Lecocq, J. Llanes-Regueiro, J. Pan, G. Petschel-Held , S. Rayner, J. Robinson, R. Schaeffer, Y. Sokona, R. Swart, H. Winkler, 2007: Sustainable Development and Mitigation. In Climate Change 2007: Mitigation. Contribution of Working Group III to the Fourth Assessment Report of the Intergovernmental Panel on Climate Change [B. Metz, O.R. Davidson, P.R. Bosch, R. Dave, L.A. Meyer (eds)], Cambridge University Press, Cambridge, United Kingdom and New York, NY, USA, 2007.

[64] S.A. Van't Klooster, M.B.A. van Asselt, Practicing the scenario-axis technique. Futures 38 (2006), 15-30.

[65] Natural Resources Canada, The Energy Technology Futures Project: Scenarios to 2050, Office of Energy Technology Futures of Natural Resources Canada, 2000.

[66] W. Bell, Foundations of Futures Studies: Human science for a new era, vol. 1: History, purposes and knowledge, Third printing ed, Transaction Publishers, New Brunswick NJ, 2000. 


\section{Working Paper}

[67] T.R. Stewart, The Delphi technique and judgmental forecasting, in: K.C. Land, S.H. Schneider (Eds.), Forecasting in the Social and Natural Sciences, D. Reidel, Dordrecht, 1987, pp. 97113.

[68] G.D. Peterson, G.S. Cumming, S.R. Carpenter, Scenario planning: a tool for conservation in an uncertain world, Conserv Biol 17 (2003) 358-366.

[69] T.H. Kwon, A scenario analysis of $\mathrm{CO}_{2}$ emission trends from car travel: Great Britain 2000-2030, Transport Policy 122 (2005) 175-184.

[70] P. Steenhof, Decomposition for emission baseline setting in China's electricity sector, Energ Policy 35 1, (2007) 280-294.

[71] E. Cornish, The study of the future. World Future Society Washington, D.C., 1977.

[72] Y. Garb, S. Pulver, S.D. Van Deveer, Scenarios in society, society in scenarios: toward a social scientific analysis of storyline-driven environmental modelling. Environ Res Lett 3 (2008) 045015 8pp.

[73] J.P. Weyant, (Ed.), EMF introduction and overview. Alternative technology strategies for climate change policy. Energ Econ Special Issue 26 (2004), 501-755.

[74] S. Jebaraj, S., Iniyan, A review of energy models. Renew Sust Energ Rev 10 (2006) 281311.

[75] D. Connolly, H. Lund, B.V. Mathiesen, M. Leahy, A review of computer tools for analysing the integration of renewable energy into various energy systems. Appl Energ 87, (2010) 1059-1082.

[76] M. Bazilian, P. Nussbaumer, H.H. Rogner, A. Brew-Hammond, V. Foster, S. Pachauri, E. Williams, M. Howells, P. Niyongabo, L. Musaba, B. Ó Gallachóir, M. Radka, D.M. Kammend, Energy access scenarios to 2030 for the power sector in sub,Saharan Africa, Utilities Policy 20 (2012) 1-16. 


\section{Working Paper}

[77] J.S. Armstrong, ed. Principles of Forecasting: A Handbook for Researchers and Practitioners. Norwell, MA: Kluwer Academic, $2001 \quad$ PP 849. http://hops.wharton.upenn.edu/forecast/

[78] H. de Jouvenel, A brief methodological guide to scenario building, Technol Forecast Soc 65 (2000) 37-48.

[79] A. Midttun, T. Baumgartner, Negotiating Energy Futures: The Politics of Energy Forecasting. Energ Policy 14 (1986) 219-241.

[80] A. Kelly, J. Lumbreras, R. Maas, T. Pignatelli, F. Ferreira, A. Engleryd, Setting national emission ceilings for air pollutants: policy lessons from an ex-post evaluation of the Gothenburg Protocol, Environ Sci Policy 131 (2010) 28-41.

[81] P.A. Pilavachi, T. Dalamaga, D. Rossetti di Valdalbero, J.F. Guilmot, Ex-post evaluation of European energy models, Energ Policy 365 (2008) 1726-1735.

[82] C. Devitt, H. Hennessy, S. Lyons, L. Murphy, R.S.J. Tol, The Energy and Environment Review. Research Series Number 19. Economic and Social Research Institute, Dublin, Ireland, 2010.

[83] UNFCCC, Report of the centralized in-depth review of the fourth national communication of Ireland. United Nations Framework Convention on Climate Change $\mathrm{FCCC} /$ IDR.4/IRL, 2009 , <http://unfccc.int/resource/docs/2009/idr/irl04.pdf>, accessed 18 January 2011.

[84] UNFCCC, Report of the in-depth review of the fifth national communication of Ireland. United Nations Framework Convention on Climate Change FCCC/ IDR.5/IRL, 2010, <http://unfccc.int/resource/docs/2010/idr/irl05.pdf>, accessed 29 March 2011.

[85] B.W. Ang, F.L. Liu, A new energy decomposition method: perfect in decomposition and consistent in aggregation. Energy 26 (6) $2001537-548$. 


\section{Working Paper}

[86] B.W. Ang, F.Q. Zhang, A survey of index decomposition analysis in energy and environmental studies. Energy 2512 (2001) 1149-1176.

[87] E. Hatzigeorgiou, H. Polatidis, D. Haralambopoulos, $\mathrm{CO}_{2}$ emissions in Greece for 19902002: A decomposition analysis and comparison of results using the Arithmetic Mean Divisia Index and Logarithmic Mean Divisia Index techniques, Energy 333 (2008) 492-499.

[88] S. Sorrell, M. Lehtonen, L. Stapleton, J. Pujol, T. Champion, Decomposing road freight energy use in the United Kingdom, Energ Policy 378 (2009) 3115-3129.

[89] E. Hatzigeorgiou, H. Polatidis, D. Haralambopoulos, D., Energy $\mathrm{CO}_{2}$ Emissions for 1990-2020: A Decomposition Analysis for EU-25 and Greece. Energ Source Part A 3220 (2010) 1908-1917.

[90] P. Agnolucci, P., Ekins, G. Iacopini, K. Anderson, A. Bows, S. Mander, S., Shackley, Different scenarios for achieving radical reduction in carbon emissions: a decomposition analysis, Ecol Econ 68 (2009) 1652-1666.

[91] P. Steenhof, C. Woudsma, E. Sparling, Greenhouse gas emissions and the surface transport of freight in Canada, Transport Res D-Tr E 115 (2006) 369-376.

[92] J.W. Sun, Energy demand in the fifteen European Union countries by 2010 -A forecasting model based on the decomposition approach. Energy 26 (2001), 549560.

[93] Author, 2012.

[94] A. Grunwald, Energy futures: Diversity and the need for assessment, Futures 43 (2011), 820-830. 